\title{
Printing of self-assembled DNA hybrid materials
}

\author{
Tom Bamford ${ }^{1}$, Raushan Nurdillayeva ${ }^{2}$, Benjamin Horrocks ${ }^{1}$ and Andrew Pike ${ }^{1 *}$
}

\footnotetext{
1) Chemical Nanosciecne Laboratory, Newcastle University, Newcastle upon Tyne, NE1 7RU

2) Khoja Akhmet Yassawi International Kazakh-Turkish University, Turkistan, 161200, Kazakhstan

${ }^{*}$ E-mail andrew.pike@,newcastle.ac.uk
}

The conductivity of DNA-templated nanowires is less than that of bulk material or other types of nanowire, and as their structure is granular they are not usually useful as interconnects. Single nanowire devices are rather fragile and a single break can destroy the device completely meaning networks or bundles of nanowires are used instead. The simple drop-casting of DNA-templated nanowires leads to the formation of networks due to the intermolecular interactions as the liquid evaporates. However, this deposition process lacks control and the final pattern is of low resolution. On the other hand, inkjet printing is the controlled deposition of material at high resolution and has been routinely used to print conductive materials. Most conductive inks contain metal nanoparticles and are formulated at concentrations much higher than DNA-templated nanowires. Here we report the use of inkjet printing to prepare patterns of DNA-hybrid materials for electrical characterisation.

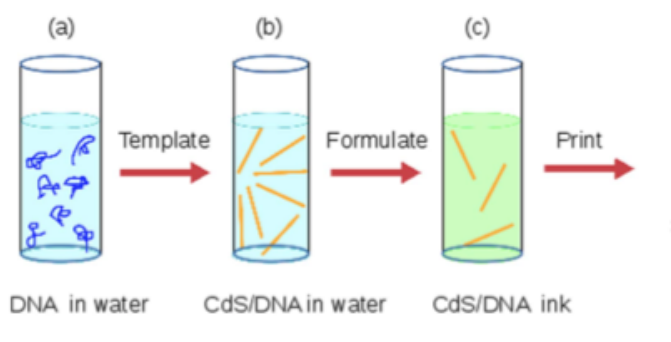

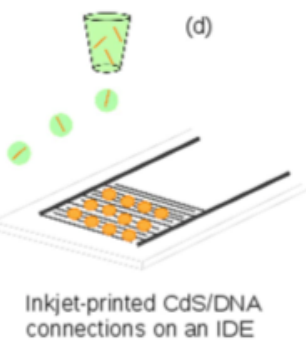

connections on an IDE

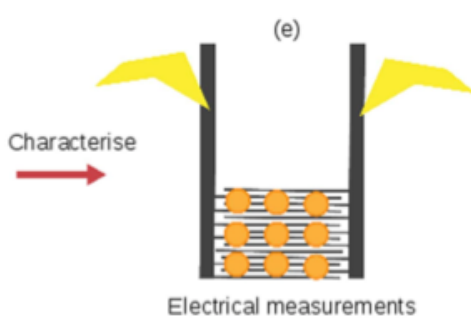

Figure 1. Schematic showing the preparation of DNA-hybrid inks for ink-jet printing. [1]

Cadmium sulfide can be templated onto $\lambda$-DNA molecules to form an aqueous dispersion of $\mathrm{CdS} / \lambda$-DNA nanowires. Subsequent addition of ethylene glycol to $50 \% \mathrm{v} / \mathrm{v}$ is sufficient to formulate an ink suitable for printing using piezoelectric drop-on-demand technology. [1, 2] Printed droplet arrays show a coffee-ring morphology of individual deposits by fluorescence and Raman microscopy, but upon increasing the number of layers of printed material by repeatedly printing over each droplet, the dry deposit approaches a disc shape. It is also possible to print parallel tracks, see Figure 2(a) and (b), by reducing the droplet separation in the array until neighbouring droplets overlap before they dry. The droplets coalesce to form a strip of width roughly equal to the diameter of the droplets.

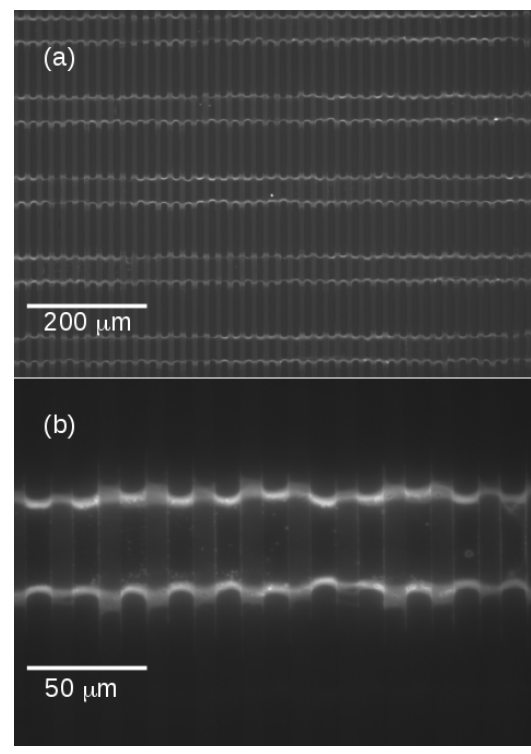

Figure 2. Printed DNA hybrid tracks. 
The Marangoni effect drives the nanowires to the edges of the strip and when dry they form parallel tracks of $\mathrm{CdS} / \lambda$-DNA nanowire bundles. Both droplets and tracks were printed onto $\mathrm{Pt} /$ glass interdigitated microelectrodes $(10 \mathrm{~m}$ width, $10 \mathrm{~m}$ gap). The current-voltage characteristics of these two-terminal devices were approximately ohmic, but with some hysteresis, which was attributed to, coupled ion motion in the films.

\section{References.}

[1] R. N. Nurdillayeva, A. B. Oshido, T. A Bamford, O. El-Zubir1, A. Houlton, J. Hedley, A. R. Pike and B. R. Horrocks, Nanotechnology, 29, 135704- (2018)

[2] R. N. Nurdillayeva, B. R. Horrocks and A. R. Pike, Materials Today Proceedings, 5, 22825- 22834, (2018). 